Supporting Information

\title{
Dramatic Effect of Carboxylic Acid on the Electronic Structure of the Active Species in Fe(PDP)-Catalyzed Asymmetric Epoxidation
}

Alexandra M. Zima, Oleg Y. Lyakin, Roman V. Ottenbacher, Konstantin P. Bryliakov, Evgenii P. Talsi*

Boreskov Institute of Catalysis, Pr. Lavrentieva 5, Novosibirsk 630090, Russian Federation Novosibirsk State University, Pirogova 2, Novosibirsk 630090, Russian Federation

*Corresponding author,e-mail: talsi@catalysis.ru

\section{Contents}

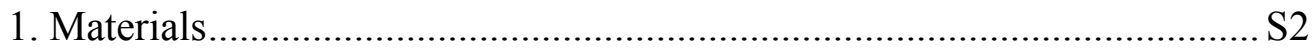

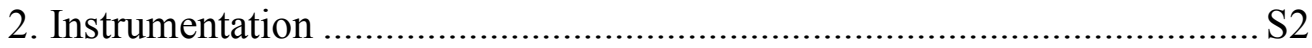

3. Sample preparation for EPR measurements............................................ S2

4. Procedure for catalytic olefin epoxidations with $\mathrm{H}_{2} \mathrm{O}_{2} \ldots \ldots \ldots \ldots \ldots \ldots \ldots \ldots \ldots \ldots \ldots . . . . . . . . . . . . . .33$

5. EPR parameters of the oxoferryl intermediates (Table S1) ...................... S4

6. Asymmetric epoxidation of chalcone (Table S2) ………………….......... S5

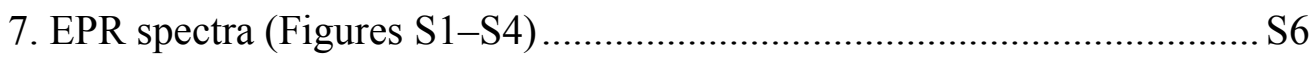

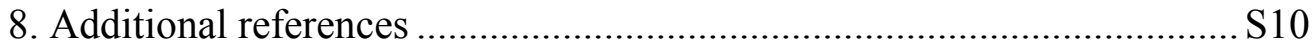




\section{Materials}

All chemicals and solvents were purchased from Aldrich, Acros Organics, or Alfa Aesar and were used without additional purification unless noted otherwise. For the EPR experiments, $\approx 95 \% \mathrm{H}_{2} \mathrm{O}_{2}$ was obtained by distillation of commercial $30 \% \mathrm{H}_{2} \mathrm{O}_{2}$ from the phosphate buffer, followed by concentration of the distillate under reduced pressure at room temperature. Caution: Concentrated hydrogen peroxide is potentially explosive and should be handled with care! The exact $\mathrm{H}_{2} \mathrm{O}_{2}$ concentrations in the prepared solutions were determined by iodometric titration under argon. Cyclohexene was purified by distillation over sodium metal in Ar. Iron complexes $\left[((S, S)-\mathrm{PDP}) \mathrm{Fe}^{\mathrm{II}}(\mathrm{OTf})_{2}\right](\mathbf{1}){ }^{\mathrm{S} 1}\left[((R, R)-\mathrm{PDP}) \mathrm{Fe}^{\mathrm{II}}(\mathrm{OTf})_{2}\right]\left(\mathbf{1}^{\boldsymbol{R}, \boldsymbol{R}}\right){ }^{\mathrm{S} 1}$ and $\left[\left((S, S)-\mathrm{PDP}^{*}\right) \mathrm{Fe}^{\mathrm{III}}(\mu-\mathrm{OH})_{2} \mathrm{Fe}^{\mathrm{III}}\left((S, S)-\mathrm{PDP}^{*}\right)\right](\mathrm{OTf})_{4}(\mathbf{5})^{8 \mathrm{a}}$ were prepared as described.

\section{Instrumentation}

EPR spectra $\left(-196^{\circ} \mathrm{C}\right)$ were measured in $3 \mathrm{~mm}$ quartz tubes on a Bruker ER-200D spectrometer at 9.39.4 GHz, modulation frequency $100 \mathrm{kHz}$, modulation amplitude $5 \mathrm{G}$. The dual EPR cavity furnished with the spectrometer was used. Periclase crystal $(\mathrm{MgO})$ with impurities of $\mathrm{Mn}^{2+}$ and $\mathrm{Cr}^{3+}$, which served as a side reference, was placed into the second compartment of the dual cavity. Measurements were conducted in a quartz finger Dewar filled with liquid nitrogen. EPR signals were quantified by double integration with a frozen solution of copper(II) acetylacetonate as a standard at $-196{ }^{\circ} \mathrm{C}$. Enantioselective chromatographic resolutions of epoxide enantiomers were performed on a Shimadzu LC-20 chromatograph equipped with a set of chiral columns as reported previously. ${ }^{8 \mathrm{a}, \mathrm{S} 2}$

\section{Sample preparation for EPR measurements}

Using a gastight microsyringe connected with polyethylene capillary, an appropriate amount of $\mathrm{H}_{2} \mathrm{O}_{2}$ in $0.05 \mathrm{~mL}$ of a $\mathrm{CH}_{2} \mathrm{Cl}_{2} / \mathrm{CH}_{3} \mathrm{CN}$ mixture was added to $0.25 \mathrm{~mL}$ of a solution of iron complex and carboxylic acid in $\mathrm{CH}_{2} \mathrm{Cl}_{2} / \mathrm{CH}_{3} \mathrm{CN}$ mixture at $-75 \ldots-65^{\circ} \mathrm{C}$ directly in a quartz $\mathrm{EPR}$ tube $(d=3 \mathrm{~mm})$. After stirring for 1-3 min with polyethylene capillary at $-80 \ldots-75^{\circ} \mathrm{C}$, the sample was frozen by immersion in liquid nitrogen, and the EPR spectrum was measured at $-196^{\circ} \mathrm{C}$. For kinetic EPR studies, this sample was placed in a thermostat at required temperature directly in the EPR tube. To stop the reaction, the tube was again immersed in liquid nitrogen, followed by registration of the EPR spectrum at $-196{ }^{\circ} \mathrm{C}$.

To measure the reactivity of intermediates of the type $1 \mathbf{a}^{\mathbf{E H A}}\left(\mathbf{1} \mathbf{a}^{\mathbf{E H A}}, \mathbf{1 a}^{\mathbf{E B A}}\right.$ and $\left.\mathbf{1 a}{ }^{\mathbf{P V A}}\right)$ towards cyclohexene oxidation, the appropriate amount of cyclohexene solution in 1.8:1 $\mathrm{CH}_{2} \mathrm{Cl}_{2} / \mathrm{CH}_{3} \mathrm{CN}$ mixture was placed to the tip of glass capillary using connected microsyringe, and frozen by immersion of capillary in liquid nitrogen. Then this capillary was rapidly (during 2-3 s) placed into the EPR tube containing frozen solution of preliminary generated intermediate of the type $1 \mathbf{a}^{\mathbf{E H A}}$, and the tube with the 
capillary inside was placed in thermostat at $-90{ }^{\circ} \mathrm{C}$. In $10-15 \mathrm{sec}$, solvent in the tube melted that allow injection of alkene solution and careful mixing the reagents by glass capillary during $<1 \mathrm{~min}$. After that, the glass capillary was removed and the decay rate of the intermediate at $-75{ }^{\circ} \mathrm{C}$ was monitored. It was found that in the presence of cyclohexene the half-life times of intermediates of the type 1a ${ }^{\text {EHA }}$ decreased at least by an order of magnitude. The blank experiments with capillary containing a 1.8:1 $\mathrm{CH}_{2} \mathrm{Cl}_{2} / \mathrm{CH}_{3} \mathrm{CN}$ mixture without cyclohexene display no changes in the decay rates of the intermediates.

\section{Procedure for catalytic olefin epoxidations with $\mathrm{H}_{2} \mathrm{O}_{2}$}

Substrate $(100 \mu \mathrm{mol})$ and carboxylic acid $(55 \mu \mathrm{mol})$ were added to the solution of 1 ( $1 \mu \mathrm{mol}, 0.7 \mathrm{mg})$ or complex $5(0.5 \mu \mathrm{mol}, 0.8 \mathrm{mg})$ in $\mathrm{CH}_{3} \mathrm{CN}(400 \mu \mathrm{L})$, and the mixture was thermostated at $0{ }^{\circ} \mathrm{C}$. Then, $100 \mu \mathrm{L}$ of the $\mathrm{H}_{2} \mathrm{O}_{2}$ solution in $\mathrm{CH}_{3} \mathrm{CN}\left(200 \mu \mathrm{mol}\right.$ of $\left.\mathrm{H}_{2} \mathrm{O}_{2}\right)$ was injected by a syringe pump over $30 \mathrm{~min}$ upon stirring. The resulting mixture was stirred for $2.5 \mathrm{~h}$ at $0^{\circ} \mathrm{C}$. The reaction was quenched with saturated aqueous solution of $\mathrm{Na}_{2} \mathrm{CO}_{3}$ and the products were extracted with pentane $(3 \times 2 \mathrm{~mL})$. The solvent was carefully removed in a stream of air, the residue was dissolved in $1 \mathrm{~mL}$ of $\mathrm{CCl}_{4}$ and dried over anhydrous $\mathrm{Na}_{2} \mathrm{SO}_{4}$. The mixture was filtered and the filtrate was analyzed by ${ }^{1} \mathrm{H}$ NMR spectroscopy as previously described. ${ }^{3 \mathrm{a}, \mathrm{S} 2}$ To measure the enantiomeric excess values of epoxides, $20 \mu \mathrm{L}$ of the $\mathrm{CCl}_{4}$ solution were collected, and the solvent was carefully removed in a stream of air. Then, the residue was dissolved in isopropanol and subjected to LC analysis as previously described. ${ }^{3 a, 8 a}$ Experimental uncertainty of enantiomer amount measurements did not exceed $\pm 1 \%$. 
Table S1. EPR Spectroscopic Data for All Oxoferryl Intermediates Discussed Herein

\begin{tabular}{|c|c|c|c|}
\hline intermediate & $g_{1}$ & $g_{2}$ & $g_{3}$ \\
\hline \multicolumn{4}{|l|}{ 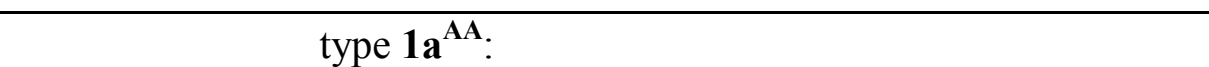 } \\
\hline $1 \mathbf{a}^{\mathbf{A A} a}$ & 2.66 & 2.42 & 1.71 \\
\hline $1 a^{B A}$ & 2.70 & 2.42 & 1.67 \\
\hline $1 a^{\mathrm{CA}}$ & 2.70 & 2.42 & 1.66 \\
\hline $1 a^{I B A}$ & 2.72 & 2.42 & 1.66 \\
\hline $1 a^{\mathrm{CHA}}$ & 2.69 & 2.42 & 1.67 \\
\hline \multicolumn{4}{|c|}{$\left[((S, S)-\mathrm{PDP}) \mathrm{Fe}^{\mathrm{V}}=\mathrm{O}(\mathrm{OC}(\mathrm{O}) \mathrm{R})\right]^{2+}$, type $\mathbf{1} \mathbf{a}^{\mathbf{E H A}}:$} \\
\hline $1 a^{E H A}$ & 2.069 & 2.007 & 1.963 \\
\hline $1 a^{E B A}$ & 2.069 & 2.007 & 1.961 \\
\hline $1 \mathbf{a}^{\mathrm{PVA}}$ & 2.069 & 2.007 & 1.962 \\
\hline \multicolumn{4}{|c|}{$\left[\left((S, S)-\mathrm{PDP}^{*}\right) \mathrm{Fe}^{\mathrm{V}}=\mathrm{O}(\mathrm{OC}(\mathrm{O}) \mathrm{R})\right]^{2+}$, type 5a: } \\
\hline $\mathbf{5} \mathbf{a}^{\mathbf{A A} b}$ & 2.071 & 2.008 & 1.960 \\
\hline $5 \mathbf{a}^{\mathrm{BA}}$ & 2.070 & 2.008 & 1.958 \\
\hline $5 \mathbf{a}^{\mathrm{CA}}$ & 2.069 & 2.008 & 1.957 \\
\hline $5 \mathbf{a}^{\mathrm{IBA}}$ & 2.069 & 2.007 & 1.957 \\
\hline $5 \mathbf{a}^{\mathrm{CHA}}$ & 2.070 & 2.008 & 1.957 \\
\hline $5 \mathbf{a}^{\mathrm{EHA}}$ & 2.070 & 2.008 & 1.958 \\
\hline $5 \mathbf{a}^{\mathrm{EBA}}$ & 2.069 & 2.008 & 1.957 \\
\hline $5 \mathbf{a}^{\mathrm{PVA}}$ & 2.069 & 2.007 & 1.958 \\
\hline
\end{tabular}

${ }^{a}$ From ref. 3a. ${ }^{b}$ From ref. 8a. 
Table S2. Asymmetric Epoxidation of Chalcone with $\mathrm{H}_{2} \mathrm{O}_{2}$ in the Presence of Enantiopure Additives ${ }^{a}$

\begin{tabular}{|c|c|c|c|c|}
\hline & 0 & $\begin{array}{l}\text { catalyst (0.5-1 mol.\%) } \\
\mathrm{H}_{2} \mathrm{O}_{2} \text { (2 equiv) } \\
\mathrm{RCOOH}(55 \text { mol. } \%)\end{array}$ & & \\
\hline entry & catalyst $^{b}$ & additive & $\begin{array}{l}\text { conversion }(\%) / \\
\text { epoxide yield }(\%)\end{array}$ & e.r. ${ }^{c}$ \\
\hline 1 & 1 & $D-(-)$-tartaric acid & $10 / 10$ & $80: 20$ \\
\hline 2 & 1 & $L-(+)$-tartaric acid & $9 / 9$ & $79: 21$ \\
\hline 3 & 5 & $D-(-)$-tartaric acid & $17 / 17$ & $81: 19$ \\
\hline 4 & 5 & $L-(+)$-tartaric acid & $18 / 18$ & $81: 19$ \\
\hline 5 & 1 & $N$-Boc- $L$-Pro & $39 / 39$ & $78: 22$ \\
\hline 6 & $1^{R, R}$ & $N$-Boc- $L$-Pro & $43 / 43$ & $79: 21$ \\
\hline
\end{tabular}

${ }^{a}$ At $0{ }^{\circ} \mathrm{C}$, [substrate]:[$\overline{\left.\mathrm{H}_{2} \mathrm{O}_{2}\right]:[a d d i t i v e]}=100 \mu \mathrm{mol}: 200 \mu \mathrm{mol}: 55 \mu \mathrm{mol}$, catalyst load $1 \mathrm{~mol} . \%$ of Fe, oxidant was added by a syringe pump over $30 \mathrm{~min}$, and the mixture was stirred for an additional $2.5 \mathrm{~h}$ followed by LC analysis. To dissolve tartaric acid, $\mathrm{H}_{2} \mathrm{O}(18 \mu \mathrm{L}, 1 \mathrm{mmol})$ was added prior to the reaction onset ${ }^{b}$ Complex $\left[((S, S)-\mathrm{PDP}) \mathrm{Fe}^{\mathrm{II}}(\mathrm{OTf})_{2}\right]$ is designated as $\mathbf{1}$, and complex $\left[((R, R)-\mathrm{PDP}) \mathrm{Fe}^{\mathrm{II}}(\mathrm{OTf})_{2}\right]$ is designated as $\mathbf{1}^{\boldsymbol{R}, \boldsymbol{R}} \cdot{ }^{c}$ Absolute configuration of chalcone epoxide was $(2 R, 3 S)$ for entries $1-5$, and $(2 S, 3 R)$ for entry 6.

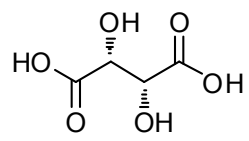

L-(+)-tartaric acid

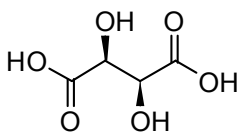

$D-(-)$-tartaric acid

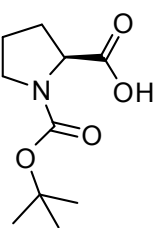

$N$-Boc-L-Pro

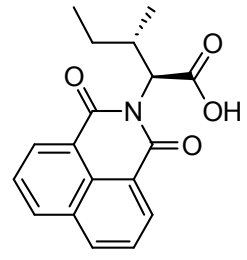

$N$-NPha-L-lleu

Previously, highly enantioselective epoxidation of substituted styrenes with aqueous $\mathrm{H}_{2} \mathrm{O}_{2}$ was described using complex 3 as the catalyst, and twelve $N$-protected amino acids as the co-ligands. ${ }^{3 \mathrm{c}}$ Since both the iron catalyst and the amino acid co-ligand were chiral, the matching-mismatching effects, resulting from the combination of the respective chiralities, were evaluated by using two enantiomeric $(R, R)$ - and $(S, S)$-forms of the catalyst. Pronounced effect (14.4 vs. 2.9 e.r.) was observed only for $N$ NPha- $L$-Ileu. ${ }^{3 \mathrm{c}}$

In this work, we have compared the e.r. values for chalcone epoxidation, using catalysts $\mathbf{1}, \mathbf{5}$ and $D$-, and $L$-tartaric acids as the catalytic additives. Virtually identical e.r. values were obtained for $D$ - and $L$ forms of the co-ligand (3.8-4 e.r. with 1, 4.3 with 5, see Table S2).

Using equivalent approach, we have evaluated the matching-mismatching effect for the epoxidation of chalcone with $\mathrm{H}_{2} \mathrm{O}_{2}$ in the presence of complexes $\left[((S, S)-\mathrm{PDP}) \mathrm{Fe}^{\mathrm{II}}(\mathrm{OTf})_{2}\right] \quad(\mathbf{1})$ and $\left[((R, R)-\mathrm{PDP}) \mathrm{Fe}^{\mathrm{II}}(\mathrm{OTf})_{2}\right]\left(\mathbf{1}^{\boldsymbol{R}, \boldsymbol{R}}\right)$ as the catalysts, and with $N$-Boc- $L$-Pro as the catalytic additive. Again very similar e.r. values were obtained in both cases (3.5 e.r. for $\mathbf{1}$, and 3.7 e.r. for $\mathbf{1}^{\boldsymbol{R}, \boldsymbol{R}}$, Table S2). These results witness negligible matching-mismatching effect for chalcone epoxidation in the presence of enantiopure catalysts $\mathbf{1}$ and $\mathbf{5}$, and enantiomerically pure catalytic additives. 


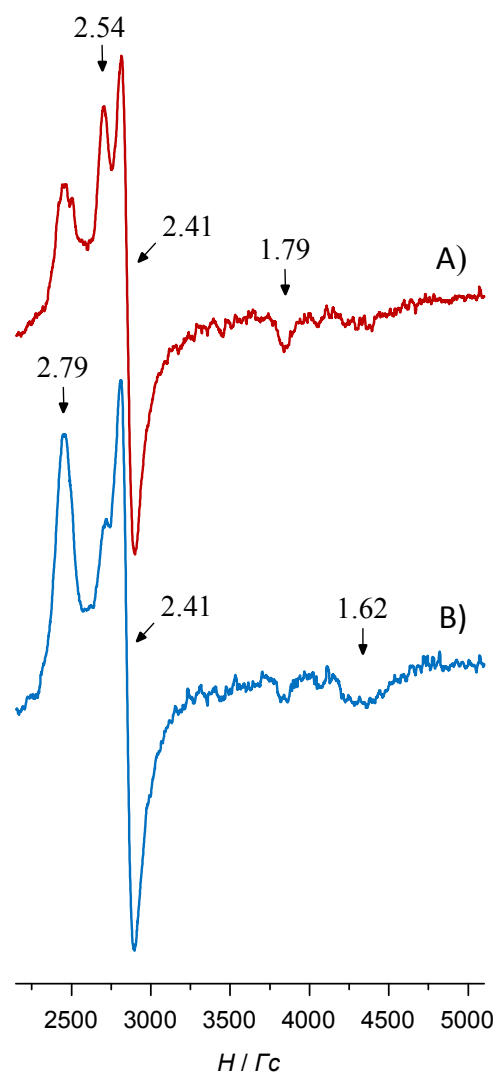

Figure S1. EPR spectra $\left(-196^{\circ} \mathrm{C}\right)$ of the samples 5/EHA $([\mathrm{Fe}]=0.04 \mathrm{M})$ frozen 10 min after mixing the reagents at room temperature in a 1.8:1 $\mathrm{CH}_{2} \mathrm{Cl}_{2} / \mathrm{CH}_{3} \mathrm{CN}$ mixture. (A) $[\mathrm{Fe}]:[\mathrm{EHA}]=10,(\mathrm{~B})[\mathrm{Fe}]:[\mathrm{EHA}]=50$.

To assign $\mathbf{1 b}$ more definitely, we have studied the interaction of the second complex $\mathrm{Fe}^{\mathrm{III}}\left(\mathrm{PDP}^{*}\right)(\mu$ $\mathrm{OH})_{2} \mathrm{Fe}^{\mathrm{III}}\left(\mathrm{PDP}^{*}\right)(5)$ considered herein with an excess of 2-ethylhexanoic acid at room temperature. In contrast to ferrous complex 1, ferric nature of the initial complex 5, together with its EPR-silence proved to be fruitful for the EPR study of stable mononuclear ferric species formed after the addition of the carboxylic acid. It was found that two types of $S=1 / 2$ ferric species form upon interaction of 5 with 2ethylhexanoic acid. At low excess of $\mathrm{RCOOH}([\mathrm{RCOOH}] /[\mathrm{Fe}]=10$, Figure S1A), mononuclear ferric complex with $g_{1}=2.54, g_{2}=2.41, g_{3}=1.79$ predominated in the solution. At high excess of RCOOH $([\mathrm{RCOOH}] /[\mathrm{Fe}]=50$, Figure S1B $)$, mononuclear ferric complex with $g_{1}=2.79, g_{2}=2.41, g_{3}=1.62$ became the predominant species. Both complexes are relatively stable at room temperature (half-life time

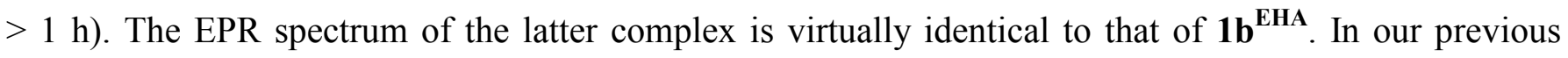
paper, species with $g_{1}=2.54, g_{2}=2.41, g_{3}=1.79$ was proposed to be ferric complex $[((S, S)$ $\left.\left.\mathrm{PDP}^{*}\right) \mathrm{Fe}^{\mathrm{III}}\left(\kappa^{2}-\mathrm{OC}(\mathrm{O}) \mathrm{R}\right)\right]^{2+} .{ }^{8 \mathrm{a}}$ Apparently, the increase of the carboxylic acid concentration may favor the formation of a ferric complex with two carboxylic ligands, e.g. [((S,S)-PDP*) $\left.\mathrm{Fe}^{\mathrm{III}}(\mathrm{OC}(\mathrm{O}) \mathrm{R})(\mathrm{RCOOH})\right]^{2+}$. Thus, $\mathbf{1} \mathbf{b}^{\text {EHA }}$ can be tentatively assigned to the complex $\left[((S, S)-\mathrm{PDP}) \mathrm{Fe}^{\mathrm{III}}(\mathrm{OC}(\mathrm{O}) \mathrm{R})(\mathrm{RCOOH})\right]^{2+}$. 

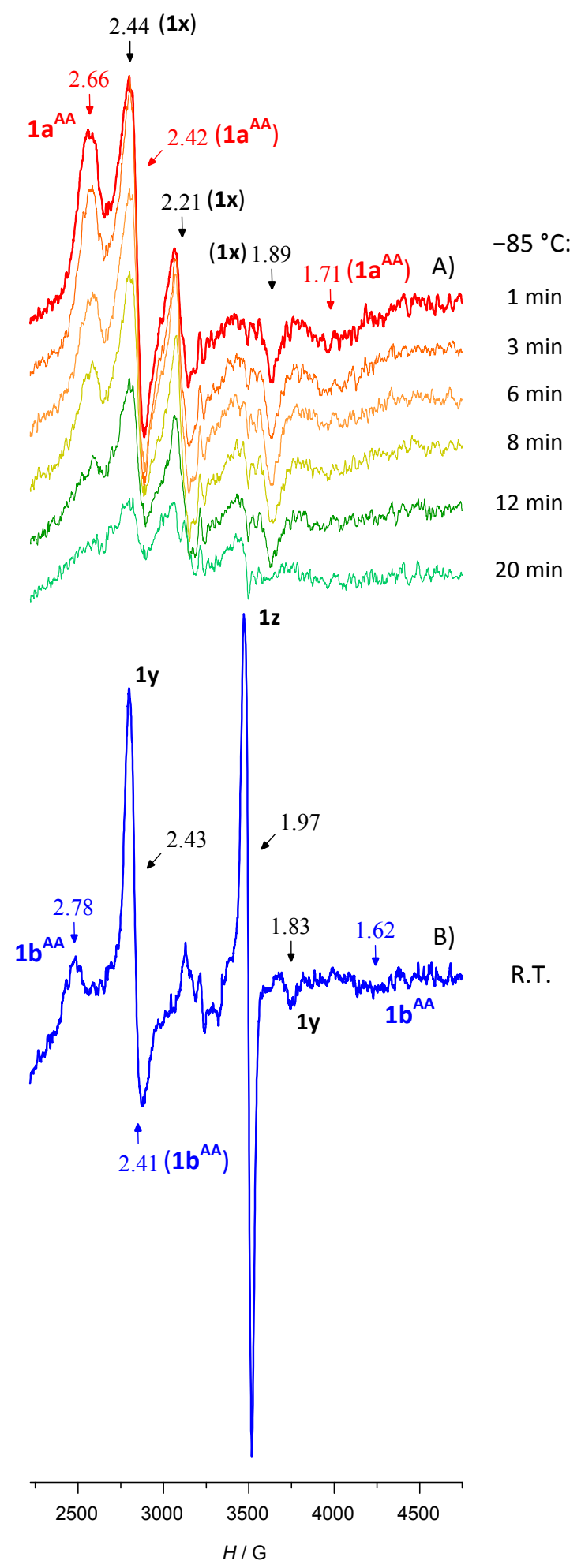

Figure S2. (A) EPR spectra $\left(-196{ }^{\circ} \mathrm{C}\right)$ of the sample $1 / \mathrm{H}_{2} \mathrm{O}_{2} / \mathrm{CH}_{3} \mathrm{COOH}\left([\mathbf{1}]:\left[\mathrm{H}_{2} \mathrm{O}_{2}\right]:\left[\mathrm{CH}_{3} \mathrm{COOH}\right]=1: 3: 10,[\mathbf{1}]=\right.$ $0.04 \mathrm{M}$ ) frozen $1 \mathrm{~min}$ after mixing the reagents at $-75^{\circ} \mathrm{C}$ in a $1.8: 1 \mathrm{CH}_{2} \mathrm{Cl}_{2} / \mathrm{CH}_{3} \mathrm{CN}$ mixture and storing the sample at $-85{ }^{\circ} \mathrm{C}$ for various times. (B) EPR spectrum $\left(-196^{\circ} \mathrm{C}\right)$ of the sample in " $\mathrm{A}$ " after storing at room temperature for 2 min. Unstable species $\mathbf{1 x}$ was previously assigned to ferric hydroxo complex [((S,S)$\left.\mathrm{PDP}) \mathrm{Fe}^{\mathrm{III}}-\mathrm{OH}\left(\mathrm{CH}_{3} \mathrm{CN}\right)\right]^{2+}$ (ref. 3a). Signals marked with $\mathbf{1 y}$ and $\mathbf{1 z}$ belong to unidentified complexes stable at room temperature. The signal of $\mathbf{1 a}^{\mathbf{A A}}$ at $g_{2}=2.42$ overlaps with the signal of $\mathbf{1} \mathbf{x}$ at $g_{1}=2.44$. The signal of $\mathbf{1} \mathbf{b}^{\mathbf{A A}}$ at $g_{2} \approx 2.41$ overlaps with the signal of $\mathbf{1 y}$ at $g_{1}=2.43$. 


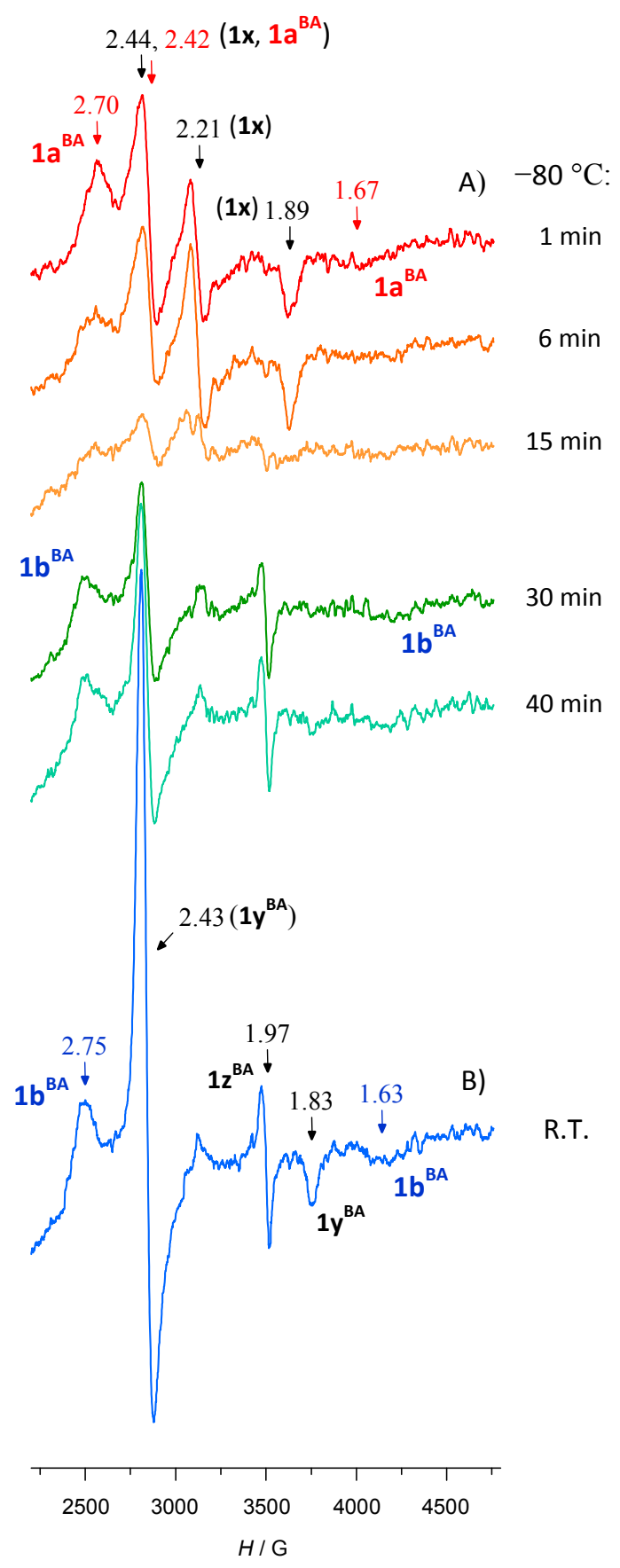

Figure S3. (A) EPR spectra $\left(-196^{\circ} \mathrm{C}\right)$ of the sample $1 / \mathrm{H}_{2} \mathrm{O}_{2} / \mathrm{BA}\left([1]:\left[\mathrm{H}_{2} \mathrm{O}_{2}\right]:[\mathrm{BA}]=1: 3: 10,[1]=0.04 \mathrm{M}\right)$ frozen 1.5 min after mixing the reagents at $-70{ }^{\circ} \mathrm{C}$ in a $1.8: 1 \mathrm{CH}_{2} \mathrm{Cl}_{2} / \mathrm{CH}_{3} \mathrm{CN}$ mixture and storing the sample at $-80{ }^{\circ} \mathrm{C}$ for various times. (B) EPR spectrum $\left(-196^{\circ} \mathrm{C}\right)$ of the sample in "A" after storing at room temperature for 2 min. Complex $\mathbf{1} \mathbf{x}$ is described in the caption for Figure S2. Unidentified complexes $\mathbf{1} \mathbf{y}^{\mathbf{B A}}$ and $\mathbf{1} \mathbf{z}^{\mathbf{B A}}$ are stable at room temperature and exhibit EPR parameters identical to those of complexes $\mathbf{1 y}$ and $\mathbf{1 z}$ in Figure S2. The signal of $\mathbf{1 a}{ }^{\mathbf{B A}}$ at $g_{2} \approx 2.42$ overlaps with the signal of $\mathbf{1} \mathbf{x}$ at $g_{1}=2.44$. The signal of $\mathbf{1} \mathbf{b}^{\mathbf{B A}}$ at $g_{2} \approx 2.42$ overlaps with the signal of $\mathbf{1 y}^{\mathbf{B A}}$ at $g_{1}=2.43$. 


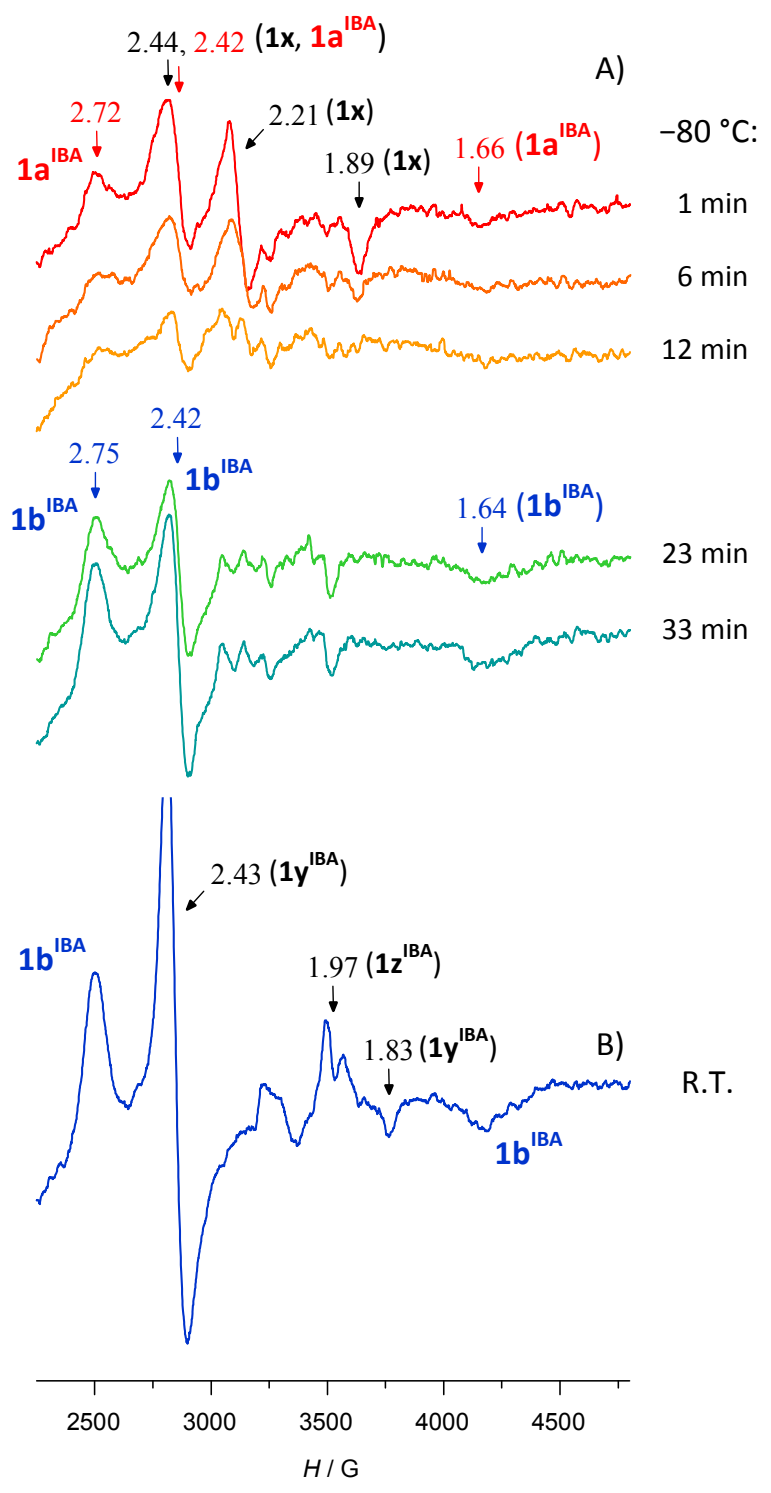

Figure S4. (A) EPR spectra $\left(-196{ }^{\circ} \mathrm{C}\right)$ of the sample $1 / \mathrm{H}_{2} \mathrm{O}_{2} / \mathrm{IBA}\left([1]:\left[\mathrm{H}_{2} \mathrm{O}_{2}\right]:[\mathrm{IBA}]=1: 3: 10,[1]=0.04 \mathrm{M}\right)$ frozen 1.5 min after mixing the reagents at $-70{ }^{\circ} \mathrm{C}$ in a $1.8: 1 \mathrm{CH}_{2} \mathrm{Cl}_{2} / \mathrm{CH}_{3} \mathrm{CN}$ mixture and storing the sample at $-80{ }^{\circ} \mathrm{C}$ for various times. (B) EPR spectrum $\left(-196^{\circ} \mathrm{C}\right)$ of the sample in "A" after storing at room temperature for 2 min. Complex $\mathbf{1 x}$ is described in the caption for Figure S2. Unidentified complexes $\mathbf{1} \mathbf{y}^{\mathbf{I B A}}$ and $\mathbf{1} \mathbf{z}^{\mathbf{I B A}}$ are stable at room temperature and exhibit EPR parameters identical to those of complexes $\mathbf{1 y}$ and $\mathbf{1 z}$ in Figure S2. The signal of $\mathbf{1 a}^{\text {IBA }}$ at $g_{2} \approx 2.42$ overlaps with the signal of $\mathbf{1} \mathbf{x}$ at $g_{1}=2.44$. 


\section{Additional References}

(S1) Suzuki, K.; Oldenburg, P. D.; Que, L., Jr. Angew. Chem. Int. Ed. 2008, 47, 1887-1889.

(S2) Ottenbacher, R. V.; Bryliakov, K. P.; Talsi, E. P. Adv. Synth. Catal. 2011, 353, 885-889. 